\title{
Durability of internally stented pericardial aortic valves: Prosthesis size matters
}

\author{
Hoda Javadikasgari, MD, Eric E. Roselli, MD, A. Marc Gillinov, MD, and Rakesh M. Suri, MD, DPhil
}

\footnotetext{
From the Department of Thoracic and Cardiovascular Surgery, Heart and Vascular Institute, Cleveland Clinic, Cleveland, Ohio.

Disclosures: A.M.G. serves as a consultant to AtriCure, Medtronic, St Jude Medical, Edwards Lifescience, Abbott Vascular, On-X, and ClearFlow, and receives research support from St Jude Medical. E.E.R. serves as a consultant and investigator for Medtronic and SORIN and as a speaker and investigator for Edwards Lifescience and St Jude Medical. R.M.S. has institutional research agreements with SORIN, St Jude Medical, Edwards Lifescience, and Abbott Vascular. H.J. has nothing to disclose with regard to commercial support.

Received for publication Oct 29, 2015; accepted for publication Oct 29, 2015; available ahead of print Nov 25, 2015.

Address for reprints: Rakesh M. Suri, MD, DPhil, Department of Thoracic and Cardiovascular Surgery, Heart and Vascular Institute, Cleveland Clinic, 9500 Euclid Ave, Cleveland, OH 44195 (E-mail: surir@ ccf.org).

J Thorac Cardiovasc Surg 2016;151:762-3

$0022-5223 / \$ 36.00$

Copyright (c) 2016 by The American Association for Thoracic Surgery

http://dx.doi.org/10.1016/j.jtcvs.2015.10.111
}

Patient preference to avoid anticoagulation and the availability of transcatheter valve-in-valve techniques have spawned efforts to reexamine bioprosthetic aortic valve durability in nonelderly patients undergoing aortic valve replacement (AVR). Although it is well understood that younger age is the main risk factor for early structural valve deterioration (SVD), lipid-lowering drugs, prosthesispatient mismatch, and higher postoperative transprosthetic gradients are probably also influential.

In their work reported in this issue of the Journal, Piccardo and colleagues ${ }^{2}$ studied durability and clinical outcomes of the Mitroflow aortic bioprosthesis (12A or LX model; SORIN SpA, Milan, Italy) in 728 patients (mean age of 76 years) who underwent AVR between 1994 and 2011. They report an overall 30-day mortality of $10.3 \%$ (75 of 728 patients), with $5.5 \%$ (20 of 359 patients) having early death in the setting of nonemergency isolated AVR, which is significantly higher than in the most recent Mitroflow series (2.7\% early deaths). ${ }^{3}$ Furthermore, Piccardo and colleagues ${ }^{2}$ determined that the mean transvalvular gradient at discharge, bioprosthetic valve size 19, and severe prosthesis-patient mismatch were associated with SVD development Curiously, however, no association was established between age and early SVD. Finally, Piccardo and colleagues ${ }^{2}$ concluded, that the risk of early SVD seems higher for the Mitroflow size 19 and this size should be reserved when the annulus enlargement is risky or there is an anatomical contraindication to sutureless or stentless valve.

Although the findings reaffirm the previously proven acceptable midterm hemodynamic performance of the Mitroflow biologic aortic valve prosthesis ${ }^{3-6}$; several important questions remain. First, what are the reasons for the higher early mortality in the present series, and how might this have affected the reported results? Second, conclusions?

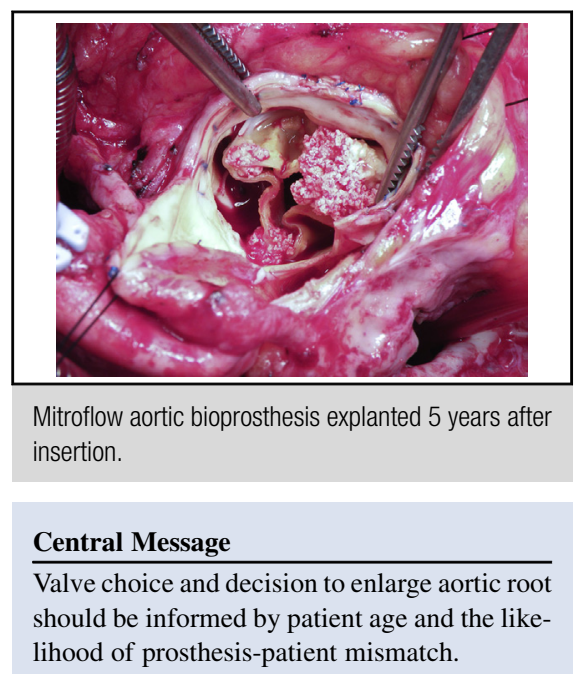

See Article page 754

what does this study tell us about bioprosthetic AVR durability in a rapidly growing population of nonelderly patients who are increasingly more likely to select bioprosthetic devices in the current era? Third, are the unadjusted comparisons between the SVD versus non-SVD groups and bioprosthesis size \#19 versus greater than \#19 robust enough to support the intended

In a contemporary study of 1003 patients (mean age of 74.8 years) who underwent AVR with the Mitroflow bioprosthesis between 2004 and 2011, Narayanan and colleagues $^{3}$ reported 27 early deaths $(2.7 \% ; 12$ [1.2\%] after isolated AVR). This study of Piccardo and colleagues ${ }^{2}$ demonstrated a significantly higher early mortality, with cardiogenic shock and multiorgan failure as the most common reasons for early death. The reasons for this elevated mortality are unclear, because patients in this population actually had fewer symptoms $(44 \%$ in New York Heart Association class III or IV vs $63.6 \%$ ), and the number of patients aged 80 years or older was lower $(26 \%$ vs $33 \%)$ than in the most recent Mitroflow series. The differences in early outcomes are noteworthy, and thus durability results during midterm follow-up must be interpreted accordingly.

Recent longitudinal studies on biologic aortic valve durability have indeed identified a probable effect of prosthesis-patient mismatch and transvalvular gradient on early SVD. ${ }^{1}$ We agree with the assertion of Piccardo 
and colleagues ${ }^{2}$ in their article that placing the most hemodynamically efficient biologic device possible is essential when selecting valve type and size or considering the performance of aortic annular enlargement. Also peculiar is the fact that patient age at implantation did not appear to influence SVD in the report of Piccardo and colleagues, ${ }^{2}$ whereas in previous studies this factor has been found to be a very important determinant of biologic valve longevity. ${ }^{1,3,7}$ Unfortunately, the current analysis, ${ }^{2}$ comparing 2 different populations (SVD [n $=30]$ vs non-SVD [n = 482]) and also bioprosthesis valve size $\# 19(\mathrm{n}=73)$ versus size greater than \#19 $(\mathrm{n}=655)$, falls short of proving definitively that either are influential without the use of risk factor adjustment to control for confounding factors. ${ }^{8}$

Despite these challenges, we propose the following take-away messages from this report and the recently published literature. First, despite the absence of anticalcification treatment of second-generation Mitroflow bovine pericardial bioprostheses, the current results reaffirm acceptable hemodynamic performance, survival, and freedom from valve-related reoperation, supporting its use in selected patients aged 60 years and older. Second, consideration should be given to recent literature noting an association between elevated postoperative transvalvular gradient and the risk of SVD in bioprosthetic valves. On the basis of this study of Piccardo and colleagues ${ }^{2}$ and other work, the risk of accelerated degeneration in those with patient-prosthesis mismatch, particularly when size \#19 or \#21 valves are implanted, warrants consideration. Finally the median duration of follow-up in this and other existing Mitroflow studies is approximately 5.5 years, $, 5,9,10$ and therefore continued clinical and hemodynamic assessments are essential to further our understanding of factors influencing long-term performance of this device.

\section{References}

1. Johnston DR, Soltesz EG, Vakil N, Rajeswaran J, Roselli EE, Sabik JF III, et al. Long-term durability of bioprosthetic aortic valves: implications from 12,569 implants. Ann Thorac Surg. 2015;99:1239-47.

2. Piccardo A, Blossier DJ, Le Guyader A, Orsel I, Sekkal S, Cornu E, et al. Fate of Mitroflow aortic bioprosthesis: an 18-year experience. J Thorac Cardiovasc Surg. 2016;151:754-61.

3. Anantha Narayanan M, Suri RM, Ugur M, Greason KL, Stulak JM, Dearani JA, et al. Predictors of survival and modes of failure after Mitroflow aortic valve replacement in 1,003 adults. Ann Thorac Surg. 2015;100:560-7.

4. García-Bengochea J, Sierra J, González-Juanatey JR, Rubio J, Vega M, Fernández AL, et al. Left ventricular mass regression after aortic valve replacement with the new Mitroflow 12A pericardial bioprosthesis. J Heart Valve Dis. 2006;15:446-51; discussion 451-2.

5. Jamieson WR, Koerfer R, Yankah CA, Zittermann A, Hayden RI, Ling H, et al. Mitroflow aortic pericardial bioprosthesis-clinical performance. Eur J Cardiothorac Surg. 2009;36:818-24.

6. Bleiziffer S, Eichinger WB, Hettich IM, Ruzicka D, Badiu CC, Guenzinger R, et al. Hemodynamic characterization of the Sorin Mitroflow pericardial bioprosthesis at rest and exercise. J Heart Valve Dis. 2009;18:95-100.

7. Minami K, Zittermann A, Schulte-Eistrup S, Koertke H, Körfer R. Mitroflow synergy prostheses for aortic valve replacement: 19 years experience with 1,516 patients. Ann Thorac Surg. 2005;80:1699-705.

8. Blackstone EH. Comparing apples and oranges. J Thorac Cardiovasc Surg. 2002;123:8-15.

9. Asch FM, Heimansohn D, Doyle D, Dembitsky W, Ferdinand FD, Swanson J, et al. Mitroflow aortic bioprosthesis 5-year follow-up: North American prospective multicenter study. Ann Thorac Surg. 2012;94:1198-203.

10. Yankah CA, Pasic M, Musci M, Stein J, Detschades C, Siniawski H, et al. Aortic valve replacement with the Mitroflow pericardial bioprosthesis: durability results up to 21 years. J Thorac Cardiovasc Surg. 2008;136:688-96. 